\title{
Evaluation of the Factors Influencing Diabetic Control among Adolescents with Type 1 Diabetes
}

\author{
Azar Pirdehghan ${ }^{1}$, Zahra Razavi², Razieh Rajabi ${ }^{3, *}$ \\ ${ }^{I}$ Associate Professor, Department of Community Medicine, School of Medicine, Hamadan University of Medical Sciences, \\ Hamadan, Iran \\ 2 Professor, Department of Pediatrics, School of Medicine, Hamadan University of Medical Sciences, Hamadan, Iran \\ ${ }^{3}$ General Practitioner, School of Medicine, Hamadan University of Medical Sciences, Hamadan, Iran
}

* Corresponding Author: Razieh Rajabi, School of Medicine, Hamadan University of Medical Sciences, Hamadan, Iran. Email: raziehrajabiii71@gmail.com

Received: 04.10 .2019

Accepted: 22.01.2020

How to Cite this Article: Pirdehghan A, Razavi Z, Rajabi R. Evaluation of the Factors Influencing Diabetic Control among Adolescents with Type 1 Diabetes. Avicenna J Clin Med. 2020; 26(4): 227-233. DOI: $10.29252 /$ ajcm.26.4.227

\section{Abstract}

Background and Objective: Type 1 diabetes is the most common metabolic and chronic disease in children and adolescents. This study aimed to evaluate the factors influencing diabetic control among adolescents with Type 1 diabetes.

Materials and Methods: This cross-sectional descriptive study was conducted on 205 patients aged 11-19 years with type 1 diabetes who referred to Endocrine Clinic of Besat Hospital, Hamadan, Iran, in 2019. The participants were selected based on a census sampling method and investigated in terms of factors affecting diabetic control. The data were analyzed in SPSS software (version 16). A p-value less than 0.05 was considered statistically significant.

Results: The mean age of the patients was $13.96 \pm 3.17$ years, and $58 \%$ of the participants were female. Moreover, the mean values of diabetes duration and Hemoglobin A1c $(\mathrm{HbAlc})$ were estimated at 5.71 \pm 3.16 years and $8.89 \pm 1.84 \%$, respectively. Regarding treatment adherence, $35.2 \%$ of the patients had poor adherence. The prevalence rate of depression, anxiety, and stress were $51.2 \%, 72.2 \%$, and $13.2 \%$ in patients, respectively. Poorly controlled diabetes based on HbAlc correlated significantly with father's unemployment status and poor family support. Furthermore, the status of diabetes control based on HbA1c level had a significant correlation with the scores of stress, anxiety, and depression. However, there was a negative and significant relationship between the status of diabetes control and the number of annual referrals to the clinic.

Conclusion: This study showed that anxiety, depression, and stress led to poor control in patients with type 1 diabetes. On the other hand, increased income and family support, as well as frequent visits to the clinic improved diabetic control.

Keywords: Adolescents, Diabetes Mellitus Type1, Etiology, Hemoglobin A Glycosylated 


\title{
بررسى عوامل اثر تذار بر كنترل ديابت نوع يك در نوجوانان
}

\author{
(iD) $*$ \\ آذر بيير دهقان'، زهرا رضوى '، راضيه رجبى
}

' ' دانشيار، گروه يزشكى اجتماعى، دانشكده يزشكى، دانشَاه علوم يزشكى همدان، همدان، ايران

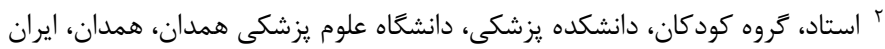

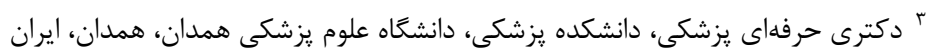

* نويسنده مسئول: راضيه رجبى، دانشكده يزشكى، دانشعاه علوم يزشكى همدان، همدان، ايران. ايميل: gmail.com

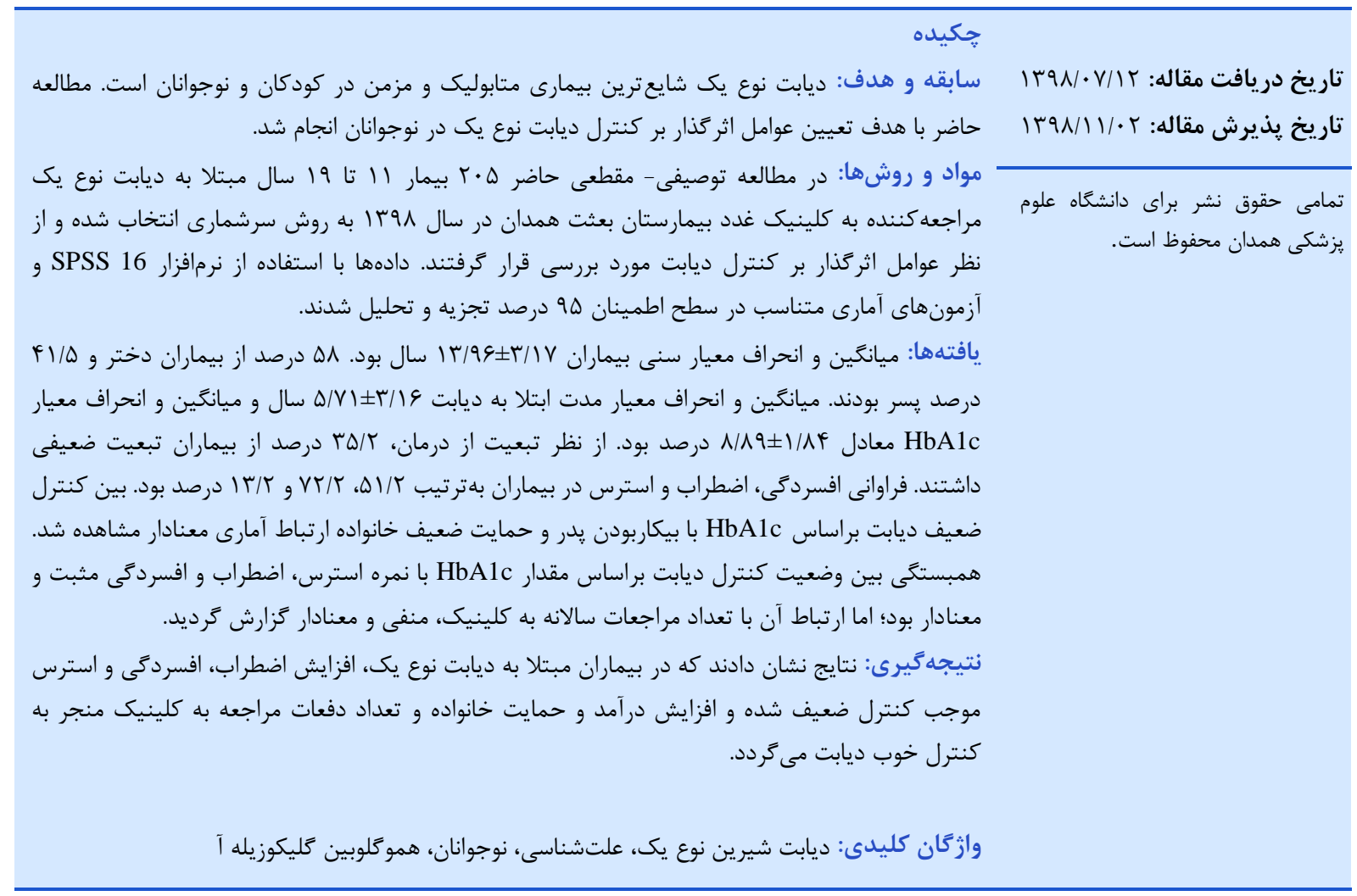

مقلdمه

بتا، سازنده انسولين بوده و منجر به كمبود انسولين بهصورت

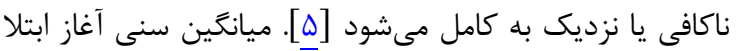

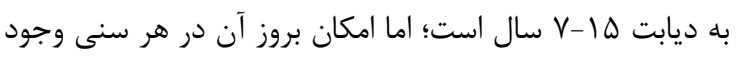

دارد [ب]

با توجه به اينكه ديابت نوع يك اكثراً در كودكان بروز

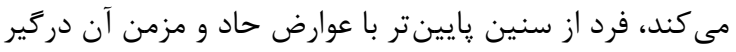

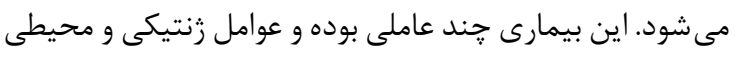

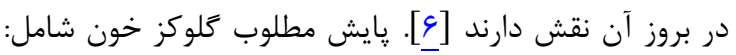

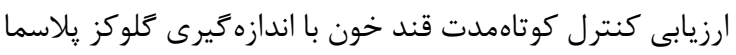

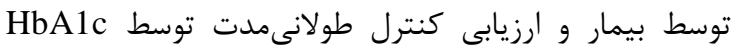

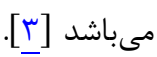
با توجه به اهميت موارد ذكرشده، مطالعه حاضر با هدف
ديابت يك اختلال ييجيده متابوليك است كه با توجه به هايير گليسمى یايدار (سطوح قند خونى كه بالاتر از نرمال است) مشخص مى گردد كه خود در نتيجه اختلال در ترشح يا عملكرد

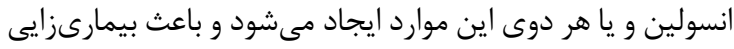
و ناتوانى مى كردد [1] دو طبقهبندى گسترده از ديابت وجود دارد: ديابت نوع يكى و

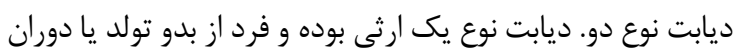

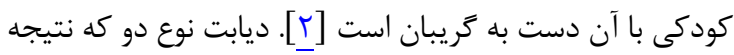

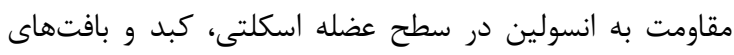
جربى مىباشد، با درجات مختلفى از تخريب سلولهاى بـ بتا همراه

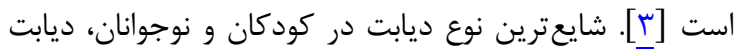

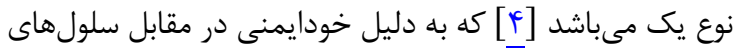


(Morisky Medication Adherence Scale) MMAS-8 استفاده شد. اين يرسشنامه توسط موريسكى و همكاران در سال

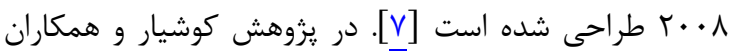
ضمن سنجش روايى صورى و محتوايى اين ابزار توسط اساتيد

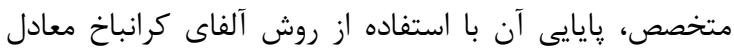

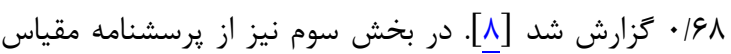
افسردگى، اضطراب و استرس De Depression ) DASS

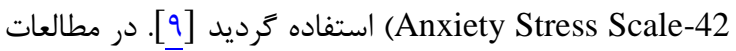
انجامشده توسط لاويبوندها، اعتبار باز آزمايى اين يرسشنامه براى

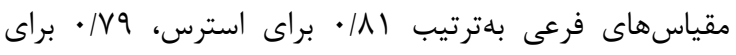

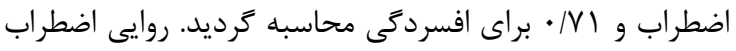

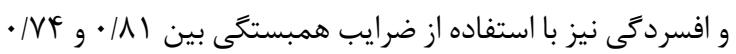

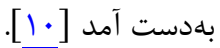
دادهها با استفاده از نرمافزار 16 SPSS و شاخدص 16 توصيفى تحليل شدند. جهت مقايسه كنترل ديابت براساس نتايج

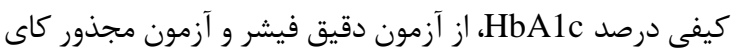
استفاده شد و براى مقايسه متغيرهاى كمى از آناليز واريانس

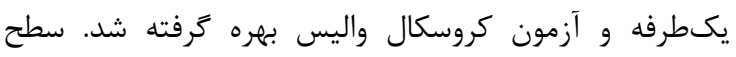

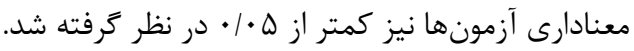

\section{يافته ها}

ميانگين و انحراف معيار سنى ه.r ب بيمار مورد بررسى

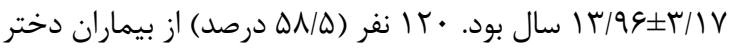

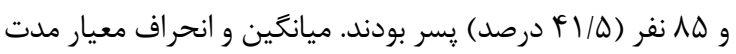

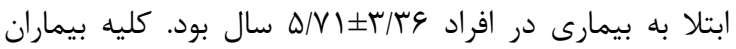

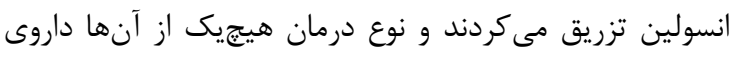

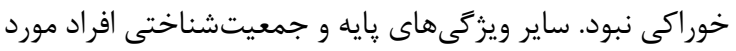

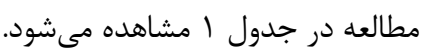

تعيين عوامل اثركذار بر كنترل ديابت نوع يك در نوجوانان انجام

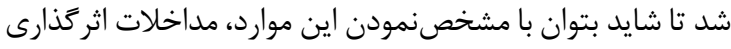

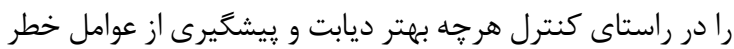

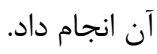

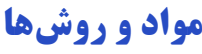

مطالعه توصيفى - مقطعى حاضر در ارتباط با نوجوانان مبتلا

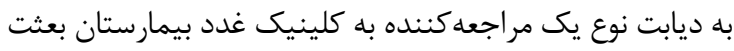

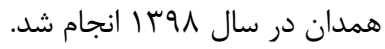

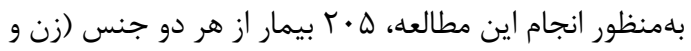

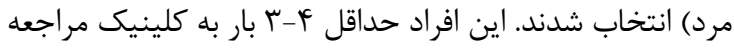

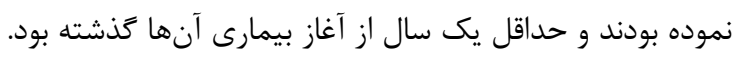
ييش از شركت در مطالعه از شركت كنندكان رضايت آكاهانه

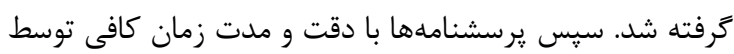

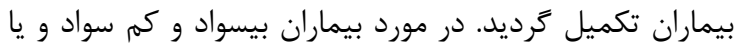

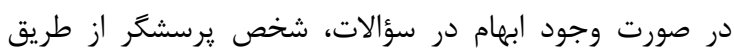

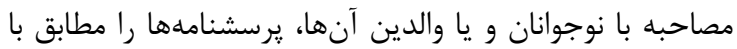

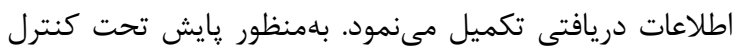

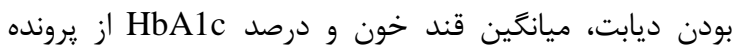
بيماران استخراج كرديد. ميزان

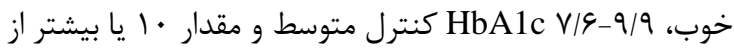
آن باعنوان كنترل ضعيف محسوب شدند [ـ]ـ.

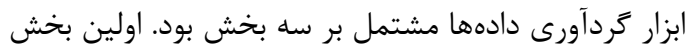

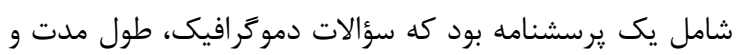

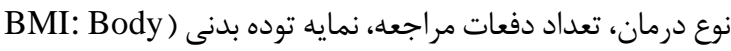
Mass Index

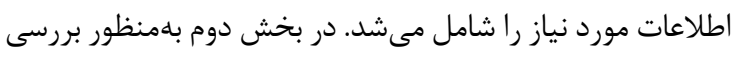

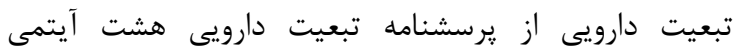

جدول ا: اطلاعات پايه بيماران مبتلا به ديابت نوع يك

\begin{tabular}{|c|c|c|c|c|}
\hline انحراف معيار \ميانگين & متغير & تعداد (درصد) & سطوح متغير & 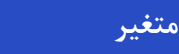 \\
\hline$q / \cdot \boldsymbol{r} \pm \Lambda / r$. & دفعات كنترل در هفته & $\begin{array}{l}(\vee q / \cdot) \text { IET } \\
(Y / /) \text { Fr } \\
(1 \cdot \cdot) r \cdot \Delta\end{array}$ & رجهر & محل سكونت \\
\hline$r / \mathscr{A} \pm \cdot / \Lambda r$ & دفعات مراجعه به كلينيك در & $\begin{array}{l}(\Lambda \Lambda / T) \backslash \Lambda \mid \\
(\Lambda / \Lambda) \backslash \Lambda \\
(Y / 9) \& \\
(1 \cdots) T \cdot \Delta\end{array}$ & سيدون بيمارى سيريدي & بيمارى همراه \\
\hline $19 / T V \pm F / T r$ & 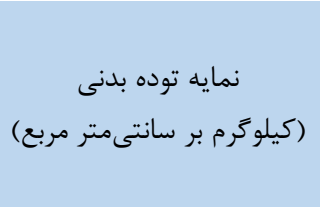 & $\begin{array}{l}(g \Delta / F) I T F \\
(Y G / T) \Delta F \\
(\Lambda / T) I V \\
(1 \cdot \cdot) T \cdot \Delta\end{array}$ & 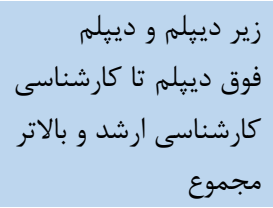 & تحصيلات يدر \\
\hline $\mid \Delta r / V G \pm \Delta \Lambda / I V$ & 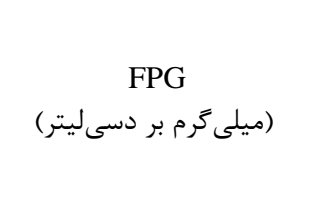 & $\begin{array}{l}(\vee q / \Delta) 1 \& r \\
(19 / \cdot) r q \\
(1 / \Delta) r \\
(1 \cdot \cdot) r \cdot \Delta\end{array}$ & كارير دييلم و دييلم & تحصيلات مادر \\
\hline
\end{tabular}




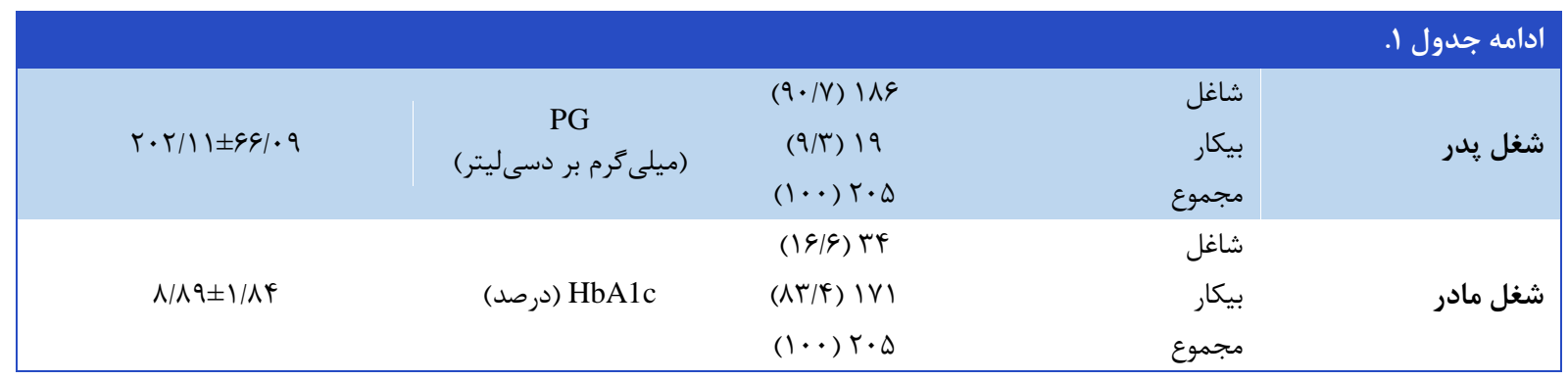

جدول ז: توزيع فراوانى وضعيت كنترل ديابت در نوجوانان مبتلا به ديابت نوع يك بر حسب ويزگكىهاى جمعيتشناختى و وضعيت حمايت خانوادكى بيماران

\begin{tabular}{|c|c|c|c|c|c|}
\hline \multirow{2}{*}{ سطح معنادارى } & \multicolumn{4}{|c|}{ سنترل ديابت متغير } & \multirow{2}{*}{ متغير } \\
\hline & تعداد (درصد) & تعداد (درصد) خوب) & تعداد (درصد) & تعداد (درصد) & \\
\hline$\cdot / 9 \Lambda \mathrm{r}^{*}$ & $\begin{array}{l}(1 \cdots) \wedge \Delta \\
(1 \cdots) \mid r .\end{array}$ & $\begin{array}{l}(Y Y / Y) \backslash 9 \\
(Y T / Q) Y V\end{array}$ & $\begin{array}{l}(\Delta \Delta / T) F V \\
(\Delta F / T) \& \Delta\end{array}$ & $\begin{array}{l}(Y T / F) 19 \\
(Y T / T) T \wedge\end{array}$ & جنسيت \\
\hline - MFY" & $\begin{array}{l}(1 \cdots) \mid \text { K } \\
(1 \cdots) \text { Fr }\end{array}$ & $\begin{array}{l}(Y T / A Y) T V \\
(Y \cdot / 9) 9\end{array}$ & $\begin{array}{l}(\Delta \& / \Lambda) q r \\
(Y \& / \Delta) r .\end{array}$ & 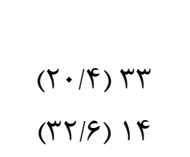 & محل سكونت \\
\hline$\cdot / V \cdot \Delta^{* * * *}$ & $\begin{array}{l}(1 \cdots) \mid T F \\
(1 \cdots) \Delta F \\
(1 \cdots) I V\end{array}$ & $\begin{array}{l}(r \cdot / I) T V \\
(r \Delta / q) \mid Y \\
(Y q / F) D\end{array}$ & $\begin{array}{l}(\Delta \Delta / T) V F \\
(\Delta / / q) Y \Lambda \\
(\Delta \Lambda / \Lambda)) .\end{array}$ & $\begin{array}{l}(Y Y / Q) T r \\
(Y T / T) \mid r \\
(I I / \Lambda) Y\end{array}$ & تحصيلات يدر \\
\hline$\left.\cdot|| f\right|^{* \text { **:* }}$ & $\begin{array}{l}(1 \cdots) \mid \varepsilon r \\
(1 \cdots) r q \\
(1 \cdots) r\end{array}$ & $\begin{array}{l}(Y T / I) T G \\
(T \cdot / Q) \wedge \\
(G 9 / V) Y\end{array}$ & 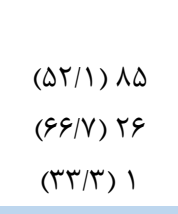 & $\begin{array}{l}(Y \Delta / \Lambda) F T \\
(I T / \Lambda) D \\
(\cdot) \cdot\end{array}$ & تحصيلات مادر \\
\hline$\cdot /\left.\cdot\right|^{* * * *}$ & $\begin{array}{l}(1 \cdots) 19 \\
(1 \cdots) 119\end{array}$ & $\begin{array}{c}(Y / T) 1 \\
(Y F / Y) F \Delta\end{array}$ & $\begin{array}{l}(r \varepsilon \mid \Lambda) V \\
(\Delta \& \mid \Delta)) \cdot \Delta\end{array}$ & $\begin{array}{l}(\Delta V / 9) 11 \\
(19 / 4) \Gamma 4\end{array}$ & شغل شيدر \\
\hline$\cdot / V \Delta \Lambda^{*}$ & $\begin{array}{l}(1 \cdots)|V| \\
(1 \cdot \cdots) r F\end{array}$ & $\begin{array}{l}(Y / Y) F . \\
(I V / V)^{G}\end{array}$ & $\begin{array}{l}(\Delta r / \Lambda) 9 r \\
(\Delta \Lambda / \Lambda) r .\end{array}$ & $\begin{array}{l}(Y Y / A) Y q \\
(Y / \Delta) \wedge\end{array}$ & شغل شار \\
\hline$\cdot / \cdot 11^{\text {w**s: }}$ & $\begin{array}{l}(1 \cdots) r \\
(1 \cdots) \Delta \Lambda \\
(1 \cdots) \mid F q\end{array}$ & $\begin{array}{l}(r K / M F) \backslash \\
(I Y / I) \vee \\
(Y G / F) Y \Lambda\end{array}$ & $\begin{array}{l}(r / T / T) 1 \\
(\Delta I / Y) r \cdot \\
(\Delta S / T) \wedge I\end{array}$ & 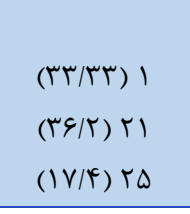 & خمايت خانواده \\
\hline
\end{tabular}

با توجه به نتايج ارائهشه در جدول rا، بين شاغل بودن

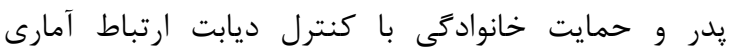

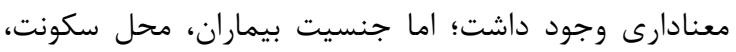

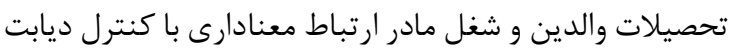
نداشتند. همبستكى بين ميزان قند خون ناشتا با تعداد مراجعات

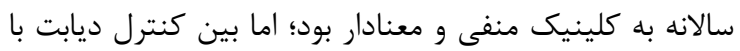

يافتها در ارتباط با كنترل ديابت براساس نتايج

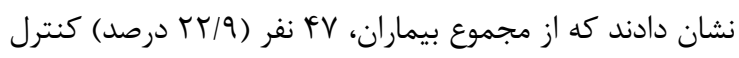

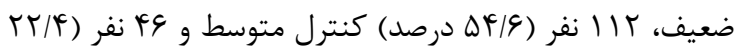

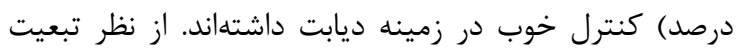

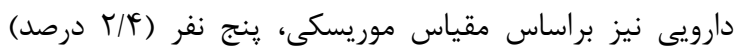

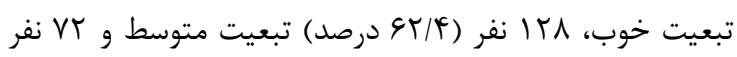

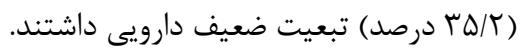


جدول با: ضريب همبستكى وضعيت كنترل ديابت در نوجوانان بر حسب متغيرهاى كمى مورد مطالعه

\begin{tabular}{|c|c|c|}
\hline سطح معنادارى & $\mathbf{R}^{*}$ & سطوح متغير \\
\hline$\cdot / 7 \wedge 9$ & $-\cdot / \cdot V^{f}$ & سن (سال) \\
\hline.$/ 9 V F$ &.$/ \cdot r$ & مدت ابتلا (سال) \\
\hline$\cdot / \Delta M F$ & $\cdot / \cdot$ FF $^{2}$ & تعداد فرزندان خانواده \\
\hline 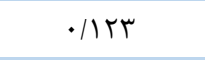 & $-\cdot / 11$ & دفعات كنترل در هفته \\
\hline$\cdot 1 \cdots 1$ & $-\cdot / T T Q$ & دفعات مراجعه به كلينيك در سال \\
\hline$\cdot \operatorname{ertr}$ & -.1 .99 & نمايه توده بدنى (كيلوكرم بر سانتىمتر مربع) \\
\hline
\end{tabular}

*Correlation: rho spearman

متوسط و خوب در بيماران حدود 90 درصد مىباشد. اين ميزان

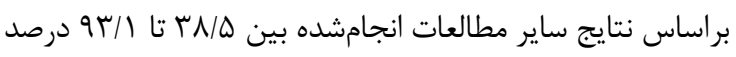

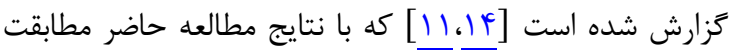

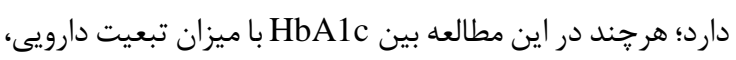
ارتباط آمارى معنادارى مشاهده نشد.

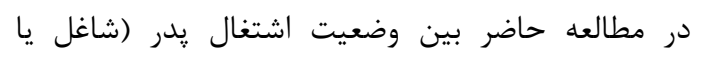

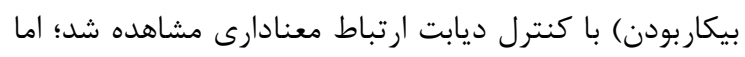

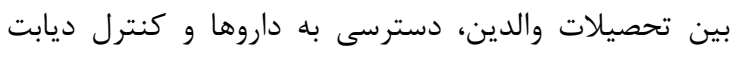

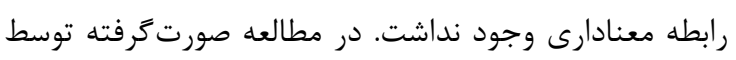

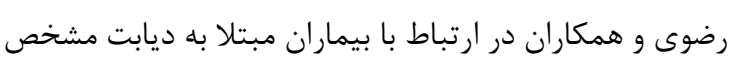

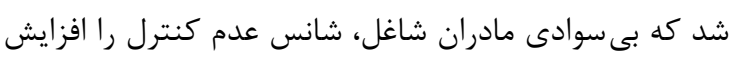

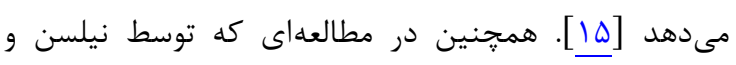

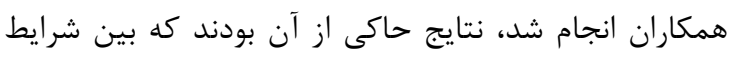

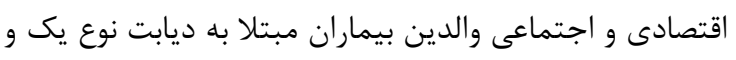

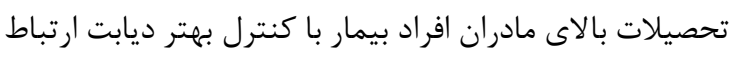

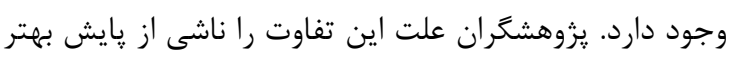

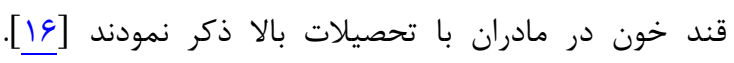

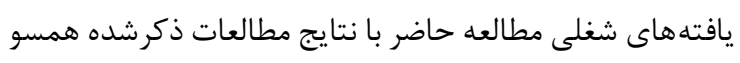
مىباشد؛ اما در مورد متغير تحصيلات والدين با مان نتايج اين

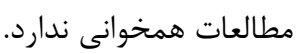

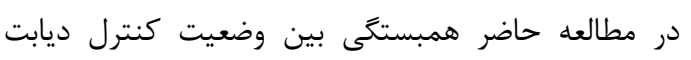
براساس مقدار HbA1c با تعداد مراجعات ساليانه به كلينيك، دماني

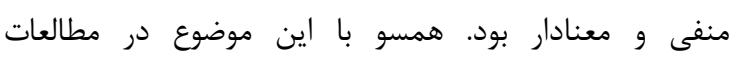

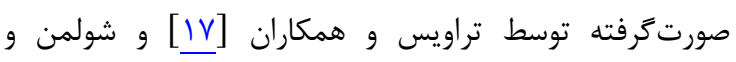

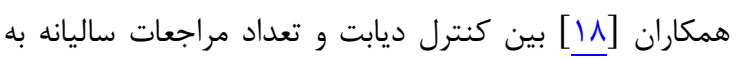

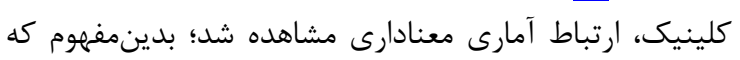

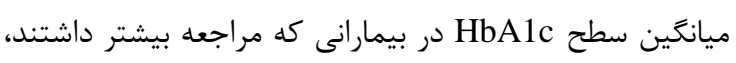

$$
\text { بلبطور معنادارى كمتر بود. }
$$

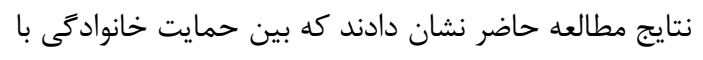

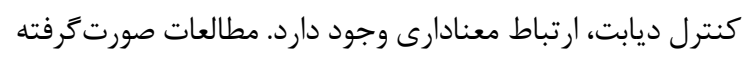

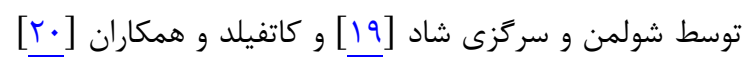

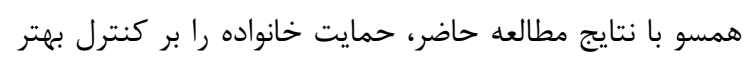

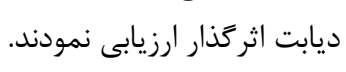

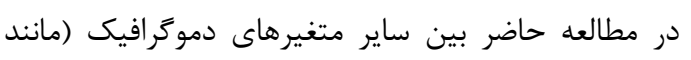
جنس، سن، محل سكونت، تعداد فرزندان و مدت زمان مان ابتلا به
سن، مدت ابتلا، تعداد فرزندان خانواده، دفعات كنترل در هفته و

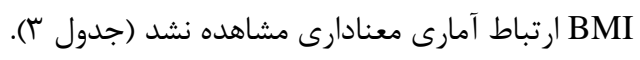

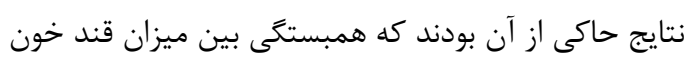

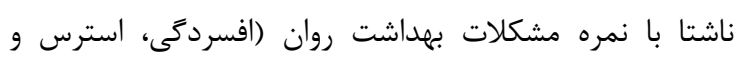

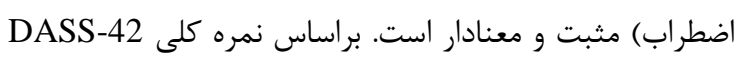

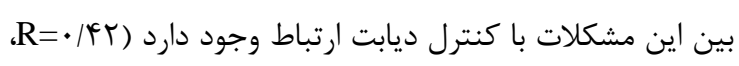

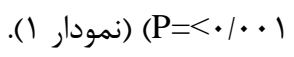

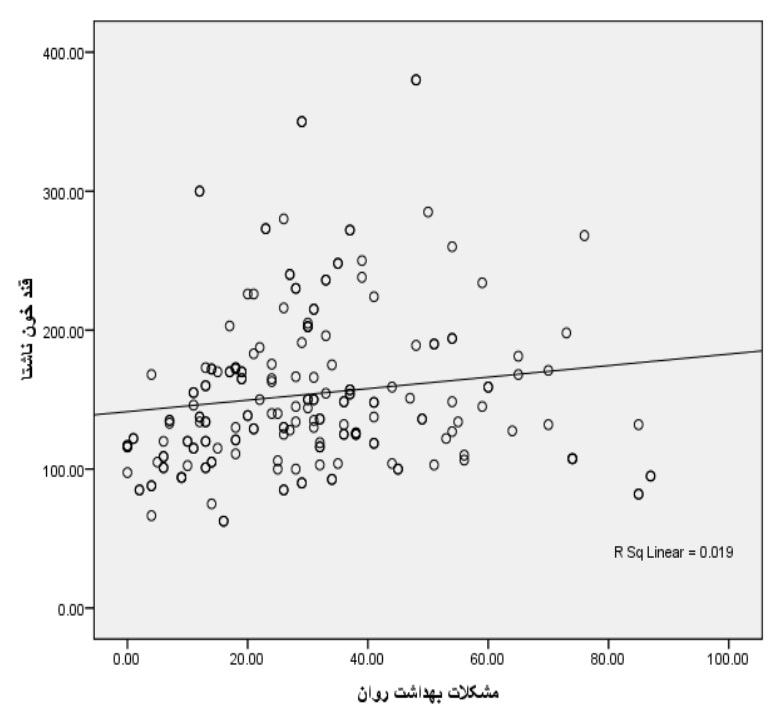

نمودار ا: ارتباط بين مشكلات بهداشت روان و ميزان قند خون ناشتا

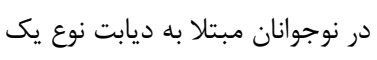

نتايج مطالعه حاضر نشان دادند كه بين افسردگى، استرس و

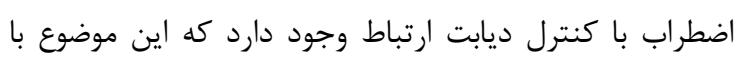

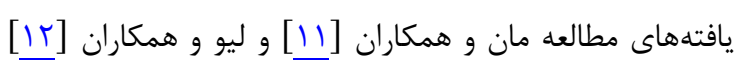

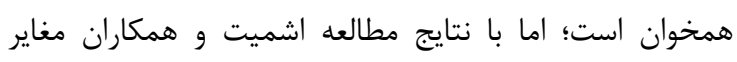

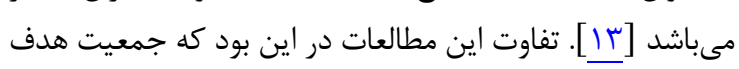

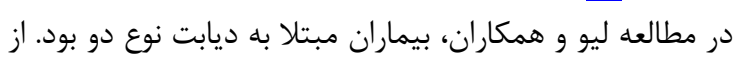

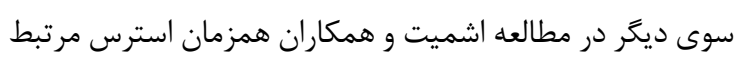

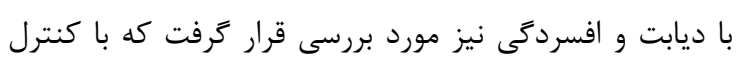
ضعيف هيير كليسمى ارتباط داشت. نتايج مطالعه حاضر نشان دادند كه ميزان تبعيت دارئ دارويى 


\section{تشك و قلر قاذى}

مقاله حاضر برگرفته از بخشى از پإياننامه دوره يزشكى

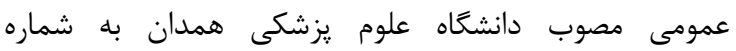
اح اء

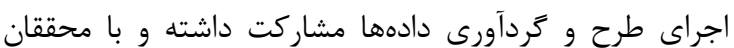
همكارى نمودند، تقدير و تشكر مى فرد

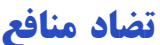
هيجز كونه تعارض منافعى بين نويسندگان و نتايج مطالعه

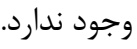

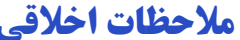

مطالعه حاضر مورد تأييد كميته اخلاق در يزوهش دانشكاه علوم يزشكى همدان مىباشد (IR.UMSHA.REC.1398.511). پيش از شركت در مطالعه از افراد شركت كننده رضايت آكاهانه كرفته شد.

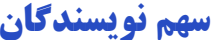

نويسنده اول (يزوهشگر اصلى): تدوين بخشهاى

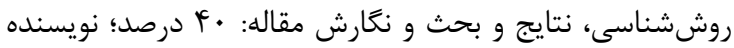

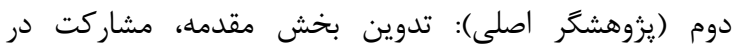

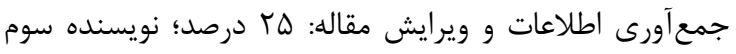

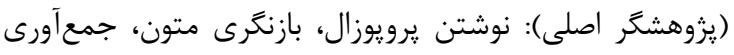

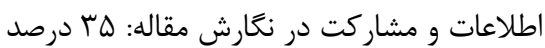

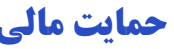

اين يروزه از سوى معاونت تحقيقات و فناورى دانشعاه علوم يزشكى همدان يشتيبانى مالى شده است.

\section{REFERENCES}

1. Barnard KD, Lloyd CE, Holt RI. Psychological burden of diabetes and what it means to people with diabetes. Psychol Diabetes Care. 2012;2:1-22. DOI.org/: 10.1007/978-085729-573-6

2. Klein HA, Lippa KD. Assuming control after system failure: type II diabetes self-management. Cog Tech Work. 2012;14(3):243-51. DOI: 10.1007/s10111-011-0206-3

3. Michael V, Richard E, Hal B, Kligman H, Behrman A. Nelson text book of pediatrics. $18^{\text {th }}$ ed. Philadelphia: Saundres Publishing; 2011. P. 2404-25.

4. Kermansaravi F, Navidian A, Ansarymoghadam A. Quality of life in type 1 diabetic adolescents in Zahedan. Iran $J$ Endocrin Metab. 2011;13(6):651-7.

5. Fauci AS, Kasper DL, Hauser SL, Jameson JL, Loscalzo J. Harrison's principles of internal medicine. New York: McGraw-Hill; 2018. P. 2851-2.

6. d'Annunzio G, Accogli A, Tallone R, Bolloli S, Lorini R. Environmental factors and type 1 diabetes mellitus in pediatric age group. In: Stanilova $S$, editors. Genes and autoimmunity - intracellular signaling and microbiome contribution. Norderstedt, Germany: BoD-Books on Demand; 2013.

7. Morisky DE, Ang A, Krousel-Wood M, Ward HJ. Predictive validity of a medication adherence measure in an outpatient setting. J Clin Hypertens. 2008;10(5):348-54. PMID: 18453793 DOI: $10.1111 / \mathrm{j} .1751-7176.2008 .07572 . \mathrm{x}$
بيمارى) با كنترل ديابت، ارتباط معنادارى مشاهده نشد؛ اما در

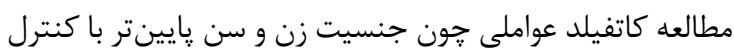
نامطلوبتر قند خون و افزايش ميزان HbA1c مرتبط بودند. دري

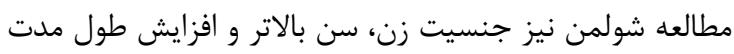

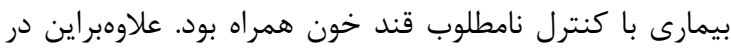

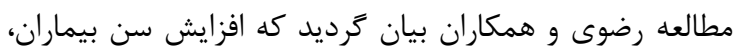

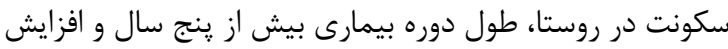

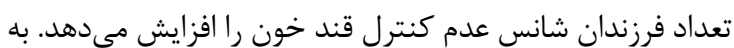
نظر مىرسد مغايرت نتايج مطالعات مذكور با مطالعه حاضر،

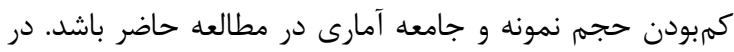

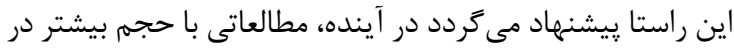
اين زمينه انجام شود. نتايج مطالعه حاضر نشان دادند كه ارتباط آمارى معنادارى بين ميزان BMI و HbA1c وجود ندارد كه اين يافته بان نتايج مطالعاتى كه توسط كاتفيلد در آمريكا انجام شد، مغاير مىباشد؛

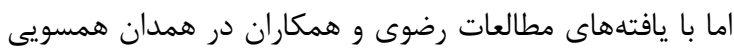

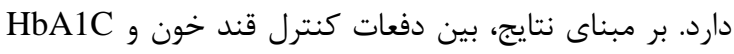

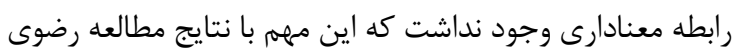

$$
\text { و همكاران مغاير مىباشد. }
$$

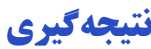

افزايش اضطراب، افسردگى و استرس در بيماران مبتلا به

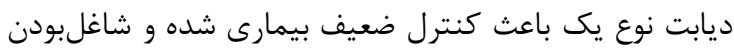

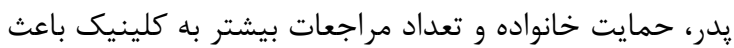

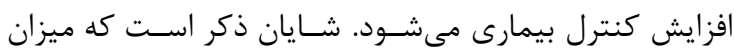

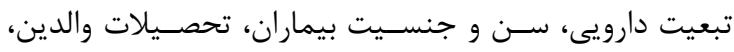

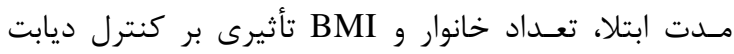
ندارد.

8. Kooshyar H, Shoorvazi M, Dalir Z, Hosseini M. Health literacy and its relationship with medical adherence and health-related quality of life in diabetic community-residing elderly. J Mazandaran Univ Med Sci. 2014;23(1):134-43. [Persian]

9. Afzali A, Delavar A, Borjali A, Mirzamani M. Psychometric properties of DASS-42 as assessed in a sample of Kermanshah high school students. J Res Behav Sci. 2007;5(2):81-92

10. Lovibond PF, Lovibond SH. The structure of negative emotional states: comparison of the Depression Anxiety Stress Scales (DASS) with the Beck Depression and Anxiety Inventories. Behav Res Ther. 1995;33(3):335-43.

11. Mann DM, Ponieman D, Leventhal H, Halm EA. Predictors of adherence to diabetes medications: the role of disease and medication beliefs. J Behav Med. 2009;32(3):278-84. PMID: 19184390 DOI: $10.1007 / \mathrm{s} 10865-009-9202-\mathrm{y}$

12. Liu YT, Lin LY, Tuan CW, Yang CY, Tang PL. Analyzing the association hbalc control by depression, social participation and utilizing self-management questionnaire. Diabetes Res Clin Pract. 2019;153:103-10. PMID: 31175913 DOI: 10.1016/j.diabres.2019.05.037

13. Schmitt A, Reimer A, Kulzer B, Haak T, Gahr A, Hermanns $\mathrm{N}$. Negative association between depression and diabetes control only when accompanied by diabetes-specific distress. J Behav Med. 2015;38(3):556-64. PMID: 25326733 DOI: 
$\underline{10.1007 / s 10865-014-9604-3}$

14. Krass I, Schieback P, Dhippayom T. Adherence to diabetes medication: a systematic review. Diabetic Med. 2015; 32(6):725-37. DOI: 10.1111/dme.12651

15. Razavi Z, Kaviani E, Fredmal J. Glycosylated hemoglobin and related factors in children with type 1 diabetes mellitus under 20 years of age. Acta Med Iran. 2018;56(8):516-21.

16. Nielsen NF, Gaulke A, Eriksen TM, Svensson J, Skipper N. Socioeconomic inequality in metabolic control among children with type 1 diabetes: a nationwide longitudinal study of 4,079 Danish children. Diabetes Care. 2019;42(8):1398405. PMID: 31123155 DOI: $10.2337 / \mathrm{dc} 19-0184$

17. Travis K, Jones A, Lyons S, Desalvo DJ. Association between glycemic control and visits with diabetes care team in youth with type 1 diabetes. Am Diabetes Assoc. 2018;67(Suppl 1):159. DOI: 10.2337/db18-159-LB

18. Shulman R, Palmert MR, Daneman D. Glycemic control in Brazilian youth with type 1 diabetes. J Pediatr. 2009;85(6):4678. PMID: 20016874 DOI: 10.2223/JPED.1954

19. Sargazi Shad T, Kermansaravi F, Navidian A. Effect of the family-centered empowerment model on quality of life and self-efficacy in adolescents with type 1 diabetes referring to the Ali Asghar's clinic in Zahedan, 2016. Iran J Endocrin Metab. 2018;19(5):330-9.

20. Cutfield SW, Derraik JGB, Reed PL, Hofman CJ, Cutfield WS. Early markers of glycaemic control in children with type1 diabetes mellitus. PLoS One. 2011;6(9):e25251. PMID: 21966469 DOI: 10.1371/journal.pone.0025251 